The evolution of income-related health inequalities in Switzerland over time

Robert E. Leu

Martin Schellhorn

04-14

September 2004

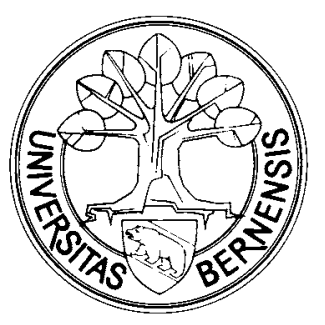

Universität Bern

Volkswirtschaftliches Institut

Gesellschaftstrasse 49

3012 Bern, Switzerland

Tel: 41 (0)316314506

Web: www.vwi.unibe.ch 


\title{
The evolution of income-related health inequalities in Switzerland over time ${ }^{\dagger}$
}

\author{
Robert E. Leu, Department of Economics, University of Bern \\ Martin Schellhorn*, Institute for the Study of Labor, IZA
}

\begin{abstract}
:
This paper presents new evidence on income-related health inequality and its development over time in Switzerland. We employ the methods lined out in van Doorslaer and Jones (2003) and van Doorslaer and Koolman (2004) measuring health using an interval regression approach to compute concentration indices and decomposing inequality into its determining factors. Nationally representative survey data for 1982, 1992, 1997 and 2002 are used to carry out the analysis. Looking at each of the four years separately the results indicates the usual positive relationship between income and health, but the distribution is among the least unequal in Europe. No clear trend emerges in the evolution of the inequality indices over the two decades. Inequality is somewhat lower in 1982 and 1992 as compared to 1997 and 2002 but the differences are not significant. The most important contributors to health inequality are income, education and activity status, in particular retirement. Regional differences including the widely varying health care supply, by contrast, do not exert any systematic influence.
\end{abstract}

Key words: Inequalities in health, concentration index, decomposition analysis

JEL Codes: D32, I10, I12

\footnotetext{
$\dagger$ The authors gratefully acknowledge partial funding through the National Research Program 45 "Future Problems of the Welfare State" of the Swiss National Science Foundation and collaboration with the members of the ECuity III project.

* Corresponding author; address: Institute for the Study of Labor, Schaumburg-Lippe-Str. 1, D- 53113

Bonn, Email: schellhorn@iza.org
} 


\section{Introduction}

Persistent differences in health and mortality by socio-economic status have long been observed in many countries. One strand of research to which the authors have contributed in previous work has focused on self-reported health and its distribution by income (Van Doorslaer et al. 1997), exploiting cross-national variations using comparable data for a number of European countries and the US. Concentration indices and curves were employed to test for differences in the extent to which self-reported health was unequally distributed across income. Van Doorslaer and Koolman (2004) have updated and extended this research using more recent data and new methods for thirteen European Union member states. Both publications reveal consistent health inequalities by income albeit with wide variations between the countries included. In van Doorslaer and Koolman (2004) Portugal in particular, but also the UK and Denmark show up with a high degree of income-related inequality, while countries like the Netherlands, Germany, but also Italy, Belgium, Spain, Austria and Ireland show a relatively low level of health inequality.

This paper looks at the evolution of income-related inequality in health in selected years and its evolution over time in Switzerland, using nationally representative data sets for 1982, 1992, 1997 and 2002, and employing the methods lined out in van Doorslaer and Jones (2003) and van Doorslaer and Koolman (2004). As in the studies mentioned above we use respondent's self assessment as our measure of general health status. An interval regression approach is employed to compute concentration indices for health. Inequality is subsequently decomposed into its determining factors to explore potential causes of income-related health inequalities in each of the four years and of differences in inequality emerging over time.

The paper is organized as follows. Section 2 sets out the methods used to measure, explain and decompose the sources of inequality. The data and variables used are described in section 3, while the results are displayed in section 4. Finally, section five provides a discussion of the results and some conclusions. 


\section{Policy Changes in Switzerland over two decades}

The Swiss health system differs in a number of important features from other health care systems. It is consumer driven in that all permanent residents have to buy a compulsory insurance package individually from one of the competing health insurance companies, choosing among a variety of plans (fee-for-service, managed care, "bonus" option). In the traditional fee-for-service sector which still accounts for over $90 \%$ of all insurance contracts policies may be differentiated by deductible levels within a range set by the government (between CHF 300 and 1500 in 2002). By contrast, there is no deductible for HMO plans which closely manage access to providers. For costs exceeding the deductible there is a coinsurance rate of $10 \%$ up to a limit which is determined by the government as well in the fee-for-service sector (presently CHF 700). In addition a copayment of CHF 10 per day is required for every hospital day. This rather extensive costsharing constitutes one of the reasons why out-of-pocket payments which may not be insured against amounted to $31.7 \%$ of total health expenditures in 2001 . A second reason is that dental care is not covered by compulsory insurance except in case of accident or severe dental problems. Premiums for compulsory insurance policies may only be differentiated by canton, type of region (urban, suburban or rural) and age (reduced premiums for children and young adults). To ease the financial hardship associated with per capita premiums, government provides means-tested benefits to low income residents. In 2001 roughly one third of the insured were subsidized to some extent, and about $15 \%$ of all enrolee premium payments were paid by the government. Subsidies are paid if the premiums exceed a certain percentage of household income - usually $8 \%$ $10 \%$. The maximum amount paid is typically the mean of the premiums of all insurance companies in the canton. Essentially, this means that the poor get free care. A more comprehensive description of the Swiss health care system is provided in Leu and Schellhorn (2004).

Most of the institutional features described above have been brought about by the 1996 reform of the Health Insurance Law. Three main goals were pursued with this major reform: a) Extension of the insurance coverage for the entire population furthering equal access (universal coverage, expansion of the compulsory basic insurance package); b) 
increase in solidarity between the healthy and the sick, the rich an the poor and men and women (flat insurance premiums, premium subsidies and universal access to compulsory health insurance); c) reduction in cost inflation (increased cost-sharing, introduction of managed care plans, possibility of enforcing fixed budgets on hospitals). There is widespread agreement that the first two goals have been achieved to a considerable degree, while cost inflation remains a major problem. Extended insurance coverage and increased solidarity can be expected to have increased equity in utilization and hence income-related equality in health. In addition, supplementary insurance coverage which is known to contribute to inequities in use has decreased since 1996 due to the extension of the compulsory insurance package. By contrast, the instruments of the revised law aiming at reducing costs, in particular increased cost-sharing and managed care options tend to reduce equity in access and might therefore have increased income-related inequality in health. Since neither explicit rationing nor sizable queues have been observed so far we do not expect, on the other hand, that the possibility of imposing a fixed budget on public hospitals has influenced the distribution of health care or health. Overall, we are left without a clear a priori hypothesis of whether the 1996 reform has increased or decreased income-related inequalities in health. Tackling this question therefore boils down to a purely empirical exercise, using nationwide representative survey data before and after 1996 and keeping in mind that other factors may have exerted an influence over this extended period of time as well.

\section{Methods}

\subsection{Measurement of health}

We use respondents' self-assessments as a measure of general health status. Selfassessed health ( $\mathrm{SAH})$ is a simple and subjective measure but has been shown to be a powerful predictor of subsequent mortality (Idler and Benyamini, 1997). Burström and Fredlund (2001) show that its predictive power does not vary systematically by SES and van Doorslaer and Gerdtham (2003) use this to carry out an analysis of inequalities in mortality. The answers to the question "How is your health in general?" which range 
from "very good" to "very bad" provide an ordinal ranking of individuals' perception of their health status. To analyze income-related inequalities in health we need to cardinalize the information contained in the SAH. Several methods have been used in the literature on health inequalities. We follow the methods lined out in van Doorslaer and Jones (2003), which were also previously applied in a cross-national comparison of health inequalities in European countries by van Doorslaer and Koolman (2004). The cumulative frequency of SAH is mapped to the empirical distribution of a generic health measure, the Canadian Health Utilities Index Mark III (HUI) which was developed by Feeny et al. (2002). To justify this procedure it is assumed that there is a stable mapping from HUI to the (latent) variable that determines SAH and that this mapping not only applies to Canadian individuals but to other European individuals as well. Upper and lower thresholds for the underlying health score of SAH are set by assigning the values of HUI which match the observed frequencies. Van Doorslaer and Jones show that this approach is superior to methods like dichotomizing the latent health score or assuming a specific underlying distribution of latent health as carried out in van Doorslaer et al. (1997).

\subsection{Measurement of inequality}

As in the related studies we are using the health concentration index as our measure of relative income related inequality. If we have a continuous measure of health (utility) $y_{i}$ then the concentration curve $L(s)$ plots the cumulative proportion of the population (ranked by income) against the cumulative proportion of health. If $L(s)$ coincides with the diagonal everyone enjoys the same health. If $L(s)$ lies below the diagonal then inequalities in health exist which favour the rich. The larger the area between $L(s)$ and the diagonal is, the larger are the inequalities. The concentration index is defined as twice the area between the concentration curve and the diagonal and is bounded between -1 and +1 . The estimation and comparison of the inequality indices at different points in time requires representative and suitably weighted sample data. Kakwani et al. (1997) derive the formula for the concentration index to be 
[1] $\quad C=\frac{2}{N \mu} \sum_{i=1}^{N} w_{i} y_{i} R_{i}-1$

where

[2] $\quad \mu=\frac{1}{N} \sum_{i=1}^{N} w_{i} y_{i}$

is the weighted mean health of the sample, $N$ is the sample size, $w_{i}$ is the sampling weight of individual $i$ (with the sum of $w_{i}$ equal to $N$ ), and $R_{i}$ is the fractional rank of the $i$ th individual. It indicates the weighted cumulative proportion of the population up the midpoint of each individual weight and is defined as

[3] $\quad R_{i}=\frac{1}{N} \sum_{j=1}^{i-1} w_{j}+\frac{1}{2} w_{i}$ where $w_{0}=0$.

Wagstaff et al. (1991) show that $C$ can be computed conveniently using the weighted covariance of $\mu$ and the fractional rank as

$$
C=\frac{2}{N \mu} \sum_{i=1}^{N} w_{i}\left(y_{i}-\mu\right)\left(R_{i}-\frac{1}{2}\right)=\frac{2}{\mu} \operatorname{cov}_{w}\left(y_{i}, R_{i}\right)
$$

\subsection{Decomposing inequality}

If health can be specified with a linear additive model of the form

$$
y_{i}=\alpha+\sum_{k} \beta_{k} x_{k i}+\varepsilon_{i}
$$

where the $x_{k}$ variables are health determinants and $\varepsilon$ is a disturbance term, then Wagstaff et al. (2003) propose a straightforward way of decomposing the measured degree of inequality. Given the relationship between health and its determinants the concentration index for $y, C$ can be written as

$$
C=\sum_{k}\left(\beta_{k} \bar{x}_{k} / \mu\right) C_{k}+G C_{\varepsilon} / \mu
$$


where $\bar{x}_{k}$ is the mean of $x_{k}, C_{k}$ is the concentration index for $x_{k}$ (defined analogously to $C$ ) and $G C_{\varepsilon}$ is the generalized concentration index for the disturbance term. This shows that the concentration index $C$ is equal to a weighted sum of the concentration indices of the $k$ regressors, where the weight for for regressor $k$ is the elasticity of $y$ with respect to $x_{k \text {. }}$. The residual component reflects the inequality in health which is not explained by systematic variation across income groups in the regressors. In the case of the interval regression approach, no residuals can be computed and the decomposition reduces to the first term of the previous equation. As the boundaries of the categories are defined with this approach it is possible to carry out interval regression which is more efficient than the standard methods of ordered probit or logit. The linear index $x_{i} \beta$ from the interval regression gives a measure of predicted health utility given an individual has characteristics $x$. This index is suitable for decomposition because it is linear and continuous.

The estimated health elasticity of determinant $k$ can be defined as

[7] $\quad \hat{\eta}_{k} \equiv \hat{\beta}_{k} \bar{x}_{k} / \mu$

which in turn can be used to rewrite the decomposition as

[8] $\hat{C}=\sum_{k} \hat{\eta}_{k} C_{k}$

The estimated health inequality is just a weighted sum of inequality in each of its determinants with the weights equal to the health elasticities of the determinants. Consequently, total inequality can be partitioned into avoidable and unavoidable components as in Kakwani et al. (1997). Following epidemiological conventions the unavoidable part is income-related health inequality due to demographics. Applying the method of indirect standardization one can compute the age-sex expected inequality as $C^{*}$ and subtract this from $C$ to obtain an estimate of potentially avoidable inequality as $I^{*}$ $=C-C^{*}$. In principle, $C^{*}$ could be derived from a prediction of $y$ on the basis of age and gender only, i.e. including only age and gender in the regression which is used to calculate $\hat{C}$. Schokkaert and van der Voorde (2004) and Gravell(2001) show that the indirect standardization approach has the advantage that only the partial effects of age 
and gender are controlled for as the estimations do not suffer from a potential omitted variable bias. Also, the unavoidability of age and gender related inequalities in health are contentious. Decomposing the total income-related inequalities into all its components leaves the decision on which inequalities are deemed acceptable to the reader. With the decomposition analysis it is possible to further disentangle the contribution of each determinant $k$ into two separate parts and to quantify the importance of these two parts. First, the impact of determinant $k$ on health is measured by the health elasticity $\eta_{k}$. Second, the degree of unequal distribution across income is measured by the (income) concentration index $C_{k}$.

\section{Data and variable definitions}

The data used in this paper were taken from four nationwide representative crosssectional data sets, the survey on Socio-Medical Indicators for the Population of Switzerland (SOMIPOPS) which was collected in 1982, and the Swiss Health Surveys (SHS) 1992, 1997 and 2002. While the latter three use almost identical questions, there are some notable differences between SOMIPOPS and the SHS data sets. First, while the information on household income in SOMIPOPS is derived from official tax records (see Leu et al. (1986)) income in the SHS data is self-reported. We cannot exclude that the substantial increase in income from 1982 to 1992 is at least partly due to this difference in data source. In the present context, this causes a problem only if the two income variables lead to a different ranking of individuals by income. Second, the self-assessed health question in SOMIPOPS has only four categories (very good, good, fair, bad) while the SAH questionnaire contains five items ranging from "very good" to "very bad". The HUI threshold values for the five SAH categories in the SHS data are taken from van Doorslaer and Jones (2003): 0, 0.428, 0.756, 0.897, 0.947 and 1. No threshold values are available in the literature for the four categories of the SAH question in the SOMIPOPS data. The relative frequencies of the three upper categories in the SOMIPOS data are only marginally larger than those of the three corresponding categories in the SHS data while the fourth lies in between the bottom two categories of the SHS data. Trying out various thresholds revealed that the results were not very sensitive to this choice. We used threshold values of $0,0.55,0.85$ and 0.947 throughout the analysis since they produced a 
predicted HUI using the SOMIPOPS SAH question which is similar in size to the one predicted using the SHS data. Nevertheless, comparability of the 1982 results with those of the subsequent survey years remains somewhat limited. Table 1 displays descriptive statistics for the four data sets. While the proportion of respondents reporting very good or good health remained remarkably stable at around $85 \%$, the prevalence of self-reported chronic conditions decreased from $39 \%$ in 1982 to $25 \%$ in 2002. Over the same period reported problems with ADL increased from 5\% to $17 \%$. However, the analysis of health inequalities pursued in this paper is based exclusively on SAH as health indicator.

\section{Results}

Table 2 presents the results from the interval regressions of health on log-income, age, gender, educational attainment, activity status, region of residence, a dummy for supplementary insurance and the individually chosen deductible in the years 1997 and 2002. The omitted reference categories are being a male at age 18-35, working full-time, living in the cantons around Lake Geneva, and having chosen the minimal mandatory deductible (150 CHF in 1997 and 230 CHF in 2002).

In all four years income has a positive and significant direct effect on health, increasing until 1997 and then dropping back to the 1992 level. While health decreases substantially with age for both genders in 1982, there appears to be no systematic age gradient in the subsequent three survey years. The 1982 age health gradient might at least in part be caused by the different collection of SAH in that year as compared to the subsequent years. An alternative explanation might be that health levels of the elderly have improved over time due to a variety of factors such as better education, higher living standards, better medical care etc. Incidentally, the lacking of a significant age health gradient also indicates that respondents tend to rate their health relative to their own health and gender group. Retired respondents report a worse SAH compared to the reference group of (fully) working individuals. The coefficient is increasing in absolute size over the years and is significant after 1992. This offers another explanation for the disappearing age effect on health after 1982. In the first observation year the number of early retirees is relatively small which leads to almost collinear variables for age over 65 and retirement. 
Thus the 1982 age gradient in health seems to pick up at least partly the retirement effect of the later years.

The effect of a higher education on health appears to be relatively stable in all four years. More educated people seem to be in better health with the coefficient for higher education ranging between 0.12 and 0.19 in all four years. The impact of the region of residence is insignificant with the exception of the Italian speaking canton of Ticino where the respondents systematically rate their health worse than in the other cantons. In the last two observation years, individuals who opted for a higher deductible were in better health than those with the mandatory minimum deductible. The main explanation for this finding appears to be that the choice of deductible contains information on unobserved aspects of health (self-selection of good risks into higher deductibles). This argument is in line with studies by Schellhorn (2001, 2002a,b), Werblow and Felder (2003) and Gardiol et al. which all point to the existence of strong health-related choices of insurance contracts.

In figure 1 we present the concentration indices for health in the four observation years along with a decomposition analysis. The CI of predicted HUI increases from 0.0036 in 1982 to 0.0045 in 2002. In a recent study van Doorslaer and Koolman (2004) compare income-related inequalities in health of $13 \mathrm{EU}$ countries. The Swiss CI is close to the countries exhibiting the lowest degree of health inequality in this study (the Netherlands and Germany) while countries with the most unequal distribution of health, Portugal and the UK, report a CI which is three to four times larger.

Figure 2 shows the result of the decomposition analysis for the four years. For most variables the $\mathrm{CI}$ stays relatively stable over time. The contributions of theses variables to inequality move in parallel to the regression coefficients discussed above. Obviously, the most important contribution to income-related inequalities in health stems from a direct income effect. The second most important contributor is higher education. In the last three observation periods activity status starts to add substantially to a pro-richdistribution of health. This effect is mainly driven by the increased contribution of 
retirement. At the same time the contribution of age disappears after 1982. As mentioned above the most likely explanation for this is that the retirement effect in 1982 is at least partly captured by age.

Looking at the decomposition analysis in more detail in table 3 indicates that the direct effect of income is by far the most important contributing factor to income-related inequalities in health. Between $55 \%$ and $62 \%$ of total inequality are explained by this direct effect in the first three observation years, which subsequently decreases to about $43 \%$ in 2002. The effect of income is the result of a pro-rich CI of log-income which is around 0.35 in all four years and a positive effect of income on health.

The second factor which contributes to a pro-rich distribution of health is high educational attainment. Obviously, income is positively correlated with education. The $\mathrm{CI}$ of having a university degree is quite large at around 0.3 . The positive effect of higher education on health may be caused by various mechanisms. Individuals with higher education tend to have a less physically demanding work environment, for example. Human capital theory on the other hand predicts that the better educated are more efficient producers of health because they have better knowledge of healthy behaviour or life styles.

A third factor which has gained importance in explaining income-related health inequalities is activity status, in particular retirement. Due to the aging of the population and early retirement schemes the proportion of retirees in our data has more than doubled from $9 \%$ in 1982 to $21 \%$ in 2002 . The CI of the dummy variable for retirement is negative, indicating that retired individuals are concentrated among those with low income. The CI for retirement reaches its minimum of -0.21 in 1992 and increases to 0.136 until 2002. This increase (in absolute value) of the $\mathrm{CI}$ indicates that the mandatory capital-funded pension system has reduced the concentration of low-income individuals among the retired in the second decade of our observation period. The estimated coefficients on retirement become significantly more negative over time. However, it is 
not clear whether retirement has a negative impact on health or whether people retire earlier because they are in bad health.

Regional differences do not seem to add systematically to income-related health inequalities in Switzerland. High incomes are concentrated in the North-West of Switzerland (the cantons of Basel City, Basel Country and Aargau) and the cantons of Zurich and Geneva but the marginal effects appear to vary unsystematically across regions.

\section{Discussion and Conclusions}

This paper adds considerably to the existing knowledge on inter-individual health disparities by income in Switzerland. First, it uses more recent data than the existing literature. Second, it is not restricted to a cross-section approach for one survey year but investigates the evolution of income-related inequality in health over the last two decades as well. Third, it achieves a more consistent and reliable estimate of the degree of health inequalities by using an interval regression approach to estimate more fully specified health (utility) equations. Finally, the decomposition method we use allows for the decomposition of total observed income-related health inequality into the contributions of the health elasticity and the inequality by income for all health determinants included in the analysis.

As expected we find income-related inequalities in health in all four observation years. However, no systematic trend emerges over time although the index value is insignificantly higher in 20002 than in 1982. Comparing the former index value to those reported in a recent study by van Doorslaer and Koolman (2004) indicates that the distribution of health by income in Switzerland is among the least unequal in Europe. Only the Netherlands exhibit lower income-related inequality in health.

That there is no systematic variation in income-related inequality over time comes at no surprise. Income inequality has not changed much over the past 20 years. The same is true for income-related inequality in health care utilization (see Leu and Schellhorn 
2004). Increased life expectancy has increased the proportion of the elderly in the population which tend to report lower self-assessed health, other things equal. This may be one of the reasons for the insignificantly higher index values in 1997 and 2002. This aging population effect may have been dampened by the fact that older residents tend to be in increasingly better health and to live independently longer for a variety of reasons such as higher living standards, better education, better nutrition or better medical care. Finally, since the 1996 health care reform has not systematically influenced utilization and its distribution by income, we cannot expect any measurable effect on health. This is compatible with the evolution of the most important health indicators, like life expectancy at birth, which tend to improve systematically over time but show no reaction to changes in the health care system (WHO 2004).

The decomposition of the measured health inequalities consistently shows in all four years that income is the most important contributor to income-related inequality. The second most important contributor is educational achievement while the third is activity status, in particular retirement. These results coincide with those of the most recent international comparison (van Doorslaer and Koolman 2004). Contrary to this study, no significant contribution of regional effects, including the widely differing health care supply, can be found for Switzerland. This coincides with the observation that there is no correlation between self-assessed health and the number of physicians by canton.

Retirement is the factor which has increased its contribution to income-related health inequality most dramatically over the last two decades. Since our analysis does not lend itself to any casual conclusions this observation is hard to interpret. In particular, it is not clear whether it is due to increased early retirement because of bad health or to retired individuals being in less good health as compared to those who are still working. This certainly is a finding that warrants further inspection.

This last point brings us to the limits of this study. As explained in section 3, the estimated health equations do not generally allow for any casual interpretation. The partial cross-sectional association between income and health as measured in the 
regression coefficient of $(\log )$ income may to some extent also reflect reverse causality or joint determination by some unobserved underlying factor. The same is true for some other variables, in particular labour force participation. A second caveat concerns the validity of the threshold values which were taken from a Canadian study by van Doorslaer and Koolman (2004) and which also influenced the values chosen for the 1982 survey. Recent research (see van Doorslaer and Koolman 2004) as well as our own computations indicates, however, that the results are not very sensitive to the choice of these threshold values. Finally, comparability of the 1982 data to the subsequent surveys is somewhat restricted. 


\section{References}

Burstöm, B. and P. Fredlund (2001): "Self-rated health: is it a good predictor of subsequent mortality among adults in lower as well as in higher social classes?", Journal of Epidemiology and Community Health 55(11): 836-840.

Feeny, D. W. Furlong, M. Boyle and G. Torrance et al. (2002): "Multi-attribute and single-attribute utility functions for the health utilities index mark 3 system", Medical Care 40(2): 113-128.

Gardiol, L., P.-Y. Geoffard and C. Nicollet (2002): "Testing for Adverse Selection and Moral Hazard: an Econometric Study of Deductibles and Health Expenditures on Swiss Insurance Claims Data", University of Lausanne, mimeo

Gravelle H. (2001): "Measuring income related inequalitiy in health: standardisation and the partial concentration index", Health Economics 12(10): 803-819.

Idler, E.L. and Y. Benyamini (1997): "Self-rated health and mortality: a review of twenty-seven community studies", Journal of Health and Social Behaviour 38(1): 21-37.

Jones, A.M. (2000), "Health Econometrics", in A.J. Culyer and J.P. Newhouse (eds.), Handbook of Health Economics, Elsevier, 265-344.

Leu, R., B. Buhmann and R.L. Frey (1986): "Die personelle Einkommens- und Vermögensverteilung der Schweiz 1982", Swiss Journal of Economics and Statistics 22: 111-142.

Leu, R.E. und M. Schellhorn (2004): "The evolution of income-related inequalities in health care utilization in Switzerland over time", Diskussionsschriften des Departements für Volkswirtschaftslehre der Universität Bern, Nr. 04.13; also IZA Discussion Paper No. 1316.

Kakwani, N., Wagstaff, A. and van Doorslaer, E. (1997), "Socioeconomic Inequality in Health: measurement, computation and statistical inference", Journal of Econometrics 77(1): 87-104.

Schellhorn, M. (2001): "The Effect of Variable Health Insurance Deductibles on the Demand for Physician Visits", Health Economics 10: 441-456.

Schellhorn, M (2002a): “A comparison of alternative methods to model endogeneity in count models. An application to the demand for health care and health insurance choice", mimeo, IZA Bonn.

Schellhorn, M (2002b): The Demand for Health Care. Swiss Evidence, Berlin, dissertation.de. 
Schokkaert E. and C. van de Voorde (2004): "Risk selection and the specification of the conventional risk adjustment formula", Journal of Health Economics (forthcoming).

Van Doorslaer E. and U.-G. Gerdtham (2003): "Does inequality in self-assessed health predict inequality in survival by income", Social Science and Medicne 57: 16211629.

Van Doorslaer E. and A.M. Jones (2003): "Inequalities in self-reported health: validation of a new approach to measurement", Journal of Health Economics 22(1): 61-78.

Van Doorslaer, E. and X. Koolman (2003): "Explaining Income-related Inequalities in Health Care Utilisation in Europe: a decomposition approach", Health Economics 13(7): 609-628.

Van Doorslaer, E, A. Wagstaff, H. Bleichrodt, S. Calonge, U. Gerdtham, M. Gerfin, J. Geurts, L. Gross, U. Häkkinen, R.E. Leu, O. O'Donnell, C. Propper, F. Puffer, M. Rodriguez, G. Sundberg and O. Winkelhake (1997): "Socioeconomic inequalities in health: some international comparisons", Journal of Health Economics 16(1): 93-112

Wagstaff, A., van Doorslaer, E. and Watanabe, N. (2003), "On Decomposing Health Sector Inequalities, with an Application to Malnutrition Inequalities in Vietnam", Journal of Econometrics, Vol. 112(1), pp. 207-223.

Werblow, A. and S. Felder (2003): "Der Einfluss von freiwilligen Selbstbehalten in der Gesetzlichen Krankenversicherung. Evidenz aus der Schweiz", Schmollers Jahrbuch 123: 235-264.

WHO (2004): The World Health Report 2004, Geneva. 
Table 1: Descriptive statistics

\begin{tabular}{l|cccc} 
& $\mathbf{1 9 8 2}$ & $\mathbf{1 9 9 2}$ & $\mathbf{1 9 9 7}$ & $\mathbf{2 0 0 2}$ \\
\hline $\mathrm{N}$ & 3981 & 9764 & 9827 & 13692 \\
SAH very good & 0.24 & 0.27 & 0.27 & 0.24 \\
SAH good & 0.63 & 0.57 & 0.58 & 0.62 \\
SAH average/fair & 0.12 & 0.12 & 0.12 & 0.11 \\
SAH bad & 0.01 & 0.03 & 0.03 & 0.03 \\
SAH very bad & & 0.01 & 0.00 & 0.00 \\
Chronic condition & 0.39 & 0.29 & 0.30 & 0.25 \\
ADL & 0.05 & 0.12 & 0.16 & 0.17 \\
In(income) & 7.42 & 7.94 & 8.12 & 7.96 \\
Male 18-35 & 0.09 & 0.19 & 0.16 & 0.12 \\
Male 35-45 & 0.21 & 0.10 & 0.11 & 0.12 \\
Male 45-64 & 0.13 & 0.15 & 0.16 & 0.18 \\
Male 65-74 & 0.06 & 0.05 & 0.05 & 0.05 \\
Male 75+ & 0.01 & 0.00 & 0.02 & 0.03 \\
Female 18-35 & 0.10 & 0.19 & 0.15 & 0.11 \\
Female 35-45 & 0.20 & 0.10 & 0.10 & 0.11 \\
Female 45-64 & 0.12 & 0.16 & 0.15 & 0.16 \\
Female 65-74 & 0.05 & 0.05 & 0.07 & 0.06 \\
Female 75+ & 0.02 & 0.00 & 0.03 & 0.05 \\
second. Education & 0.49 & 0.57 & 0.63 & 0.64 \\
University degree & 0.16 & 0.22 & 0.18 & 0.18 \\
employed & 0.40 & 0.53 & 0.58 & 0.60 \\
self-employed & - & 0.09 & 0.10 & 0.10 \\
part-time & 0.12 & - & - & \\
housewife /-man & 0.36 & 0.18 & 0.08 & 0.06 \\
trainee & 0.02 & 0.08 & 0.02 & 0.01 \\
retired & 0.09 & 0.11 & 0.19 & 0.21 \\
unemployed & 0.00 & 0.01 & 0.02 & 0.01 \\
Lale Geneva & 0.16 & 0.17 & 0.18 & 0.19 \\
Espace Mittelland & 0.23 & 0.24 & 0.23 & 0.24 \\
North-West CH & 0.16 & 0.14 & 0.14 & 0.13 \\
Zurich & 0.14 & 0.17 & 0.17 & 0.18 \\
East CH & 0.17 & 0.14 & 0.14 & 0.13 \\
Central CH & 0.09 & 0.09 & 0.09 & 0.09 \\
Ticino & 0.05 & 0.04 & 0.05 & 0.05 \\
Suppl. Insurance & 0.50 & 0.53 & 0.39 & 0.31 \\
HMO & & & 0.04 & 0.06 \\
Deductible 150/230 & & & 0.58 & 0.37 \\
Deductible 300/400 & & & 0.31 & 0.25 \\
Deductible 600 & & & 0.01 & 0.16 \\
Deductible 1200 & & & 0.08 & 0.05 \\
Deductible 1500 & & & 0.02 & 0.17 \\
& & & &
\end{tabular}


Table 2: Health interval regression

\begin{tabular}{|c|c|c|c|c|c|c|c|c|}
\hline & \multicolumn{2}{|c|}{1982} & \multicolumn{2}{|c|}{1992} & \multicolumn{2}{|c|}{1997} & \multicolumn{2}{|c|}{2002} \\
\hline & coef. & t-value & coef. & t-value & coef. & t-value & coef. & $\mathrm{t}$-value \\
\hline $\operatorname{lninc}$ & 0.004 & 3.16 & 0.005 & 3.28 & 0.010 & 3.45 & 0.006 & 4.04 \\
\hline Male $35-45$ & -0.002 & -0.45 & -0.003 & -1.18 & -0.009 & -3.34 & -0.005 & -2.38 \\
\hline Male $45-64$ & -0.022 & -4.71 & -0.012 & -4.74 & -0.012 & -4.03 & -0.011 & -4.67 \\
\hline Male $65-74$ & -0.034 & -3.89 & -0.004 & -0.69 & 0.009 & 1.45 & 0.018 & 3.51 \\
\hline Male $75+$ & -0.040 & -2.71 & 0.001 & 0.06 & 0.015 & 1.90 & 0.001 & 0.11 \\
\hline Female 18-35 & 0.000 & -0.08 & -0.004 & -1.60 & -0.002 & -0.76 & 0.000 & -0.01 \\
\hline Female 35-45 & -0.006 & -1.16 & -0.005 & -1.47 & -0.010 & -3.25 & -0.004 & -1.77 \\
\hline Female 45-64 & -0.024 & -4.30 & -0.012 & -4.56 & -0.009 & -3.47 & -0.006 & -2.69 \\
\hline Female 65-74 & -0.029 & -4.21 & -0.008 & -1.52 & 0.008 & 1.36 & 0.015 & 2.44 \\
\hline Female $75+$ & -0.069 & -4.70 & -0.318 & -5.10 & 0.009 & 1.30 & 0.009 & 1.45 \\
\hline second. Education & 0.012 & 3.85 & 0.010 & 4.07 & 0.014 & 4.95 & 0.014 & 6.22 \\
\hline University degree & 0.019 & 5.05 & 0.013 & 4.52 & 0.018 & 5.91 & 0.014 & 5.38 \\
\hline self-employed & & & 0.002 & 1.08 & 0.002 & 0.91 & 0.000 & 0.05 \\
\hline part-time & -0.015 & -3.38 & & & & & & \\
\hline housew ife /-man & 0.001 & 0.41 & 0.000 & 0.03 & -0.001 & -0.53 & -0.003 & -0.90 \\
\hline trainee & 0.022 & 3.76 & 0.010 & 3.10 & 0.009 & 2.79 & 0.006 & 0.96 \\
\hline retired & -0.005 & -0.71 & -0.017 & -3.31 & -0.034 & -6.02 & -0.036 & -7.36 \\
\hline unemployed & -0.059 & -1.12 & -0.016 & -1.75 & -0.017 & -1.72 & -0.020 & -2.49 \\
\hline Espace Mittelland & 0.001 & 0.25 & -0.002 & -0.76 & -0.001 & -0.29 & 0.000 & -0.19 \\
\hline North-West CH & -0.001 & -0.13 & -0.011 & -4.27 & -0.001 & -0.55 & -0.007 & -2.95 \\
\hline Zurich & 0.011 & 2.68 & -0.007 & -2.80 & -0.007 & -2.13 & -0.001 & -0.65 \\
\hline East $\mathrm{CH}$ & 0.006 & 1.44 & -0.005 & -1.87 & -0.001 & -0.51 & 0.000 & 0.12 \\
\hline Central $\mathrm{CH}$ & 0.010 & 2.03 & -0.006 & -2.00 & 0.000 & 0.15 & 0.002 & 0.93 \\
\hline Ticino & -0.018 & -2.14 & -0.016 & -3.47 & -0.014 & -3.66 & -0.010 & -3.59 \\
\hline Suppl. Insurance & 0.001 & 0.20 & 0.006 & 4.08 & 0.001 & 0.46 & 0.002 & 1.48 \\
\hline $\mathrm{HMO}$ & & & & & 0.003 & 1.07 & 0.000 & 0.17 \\
\hline Deductible $300 / 400$ & & & & & 0.000 & 0.18 & 0.000 & -0.22 \\
\hline Deductible 600 & & & & & 0.001 & 0.09 & 0.005 & 3.07 \\
\hline Deductible 1200 & & & & & 0.005 & 1.57 & 0.007 & 2.89 \\
\hline Deductible 1500 & & & & & 0.013 & 3.81 & 0.012 & 7.35 \\
\hline Constant & 0.860 & 60.35 & 0.8813 & 69.7900 & 0.841 & 37.23 & 0.865 & 68.88 \\
\hline
\end{tabular}


Table 3: Concentration Indices and Decomposition

\begin{tabular}{|c|c|c|c|c|c|c|c|c|c|c|c|c|}
\hline & \multicolumn{3}{|c|}{1982} & \multicolumn{3}{|c|}{1992} & \multicolumn{3}{|c|}{1997} & \multicolumn{3}{|c|}{2002} \\
\hline & $\mathrm{Cl}$ & $\mathrm{ME}$ & Contrib & $\mathrm{Cl}$ & $\mathrm{ME}$ & Contrib & $\mathrm{Cl}$ & $\mathrm{ME}$ & Contrib & $\mathrm{Cl}$ & $\mathrm{ME}$ & Contrib \\
\hline $\begin{array}{l}\text { HUl predicted } \\
\text { I* }^{*}\end{array}$ & 0.003636 & & & 0.00325 & & & 0.00474 & & & 0.00446 & & \\
\hline Ininc & 0.035 & 0.004 & $59.01 \%$ & 0.037 & 0.005 & $55.11 \%$ & 0.032 & 0.010 & $62.80 \%$ & 0.035 & 0.006 & $42.63 \%$ \\
\hline Male $35-45$ & 0.072 & -0.002 & $-1.12 \%$ & 0.040 & -0.003 & $-0.47 \%$ & 0.076 & -0.009 & $-1.89 \%$ & 0.030 & -0.005 & $-0.44 \%$ \\
\hline Male 45-64 & 0.143 & -0.022 & $-17.02 \%$ & 0.097 & -0.012 & $-6.20 \%$ & 0.190 & -0.012 & $-9.12 \%$ & 0.045 & -0.011 & $-2.21 \%$ \\
\hline Male $65-74$ & 0.125 & -0.034 & $-10.03 \%$ & -0.100 & -0.004 & $0.77 \%$ & 0.011 & 0.009 & $0.13 \%$ & -0.078 & 0.018 & $-1.91 \%$ \\
\hline Male $75+$ & -0.238 & -0.040 & $5.16 \%$ & -0.318 & 0.001 & $0.00 \%$ & -0.135 & 0.015 & $-1.20 \%$ & -0.116 & 0.001 & $-0.07 \%$ \\
\hline Female $18-35$ & -0.153 & 0.000 & $0.25 \%$ & -0.019 & -0.004 & $0.45 \%$ & -0.041 & -0.002 & $0.24 \%$ & 0.046 & 0.000 & $0.00 \%$ \\
\hline Female $35-45$ & 0.007 & -0.006 & $-0.32 \%$ & -0.034 & -0.005 & $0.56 \%$ & -0.086 & -0.010 & $2.15 \%$ & -0.055 & -0.004 & $0.62 \%$ \\
\hline Female 45-64 & 0.063 & -0.024 & $-6.98 \%$ & -0.004 & -0.012 & $0.24 \%$ & 0.022 & -0.009 & $-0.76 \%$ & 0.037 & -0.006 & $-0.95 \%$ \\
\hline Female $65-74$ & -0.144 & -0.029 & $9.14 \%$ & -0.328 & -0.008 & $4.40 \%$ & -0.285 & 0.008 & $-3.95 \%$ & -0.164 & 0.015 & $-3.72 \%$ \\
\hline Female $75+$ & -0.261 & -0.069 & $16.04 \%$ & 0.026 & -0.318 & $-0.63 \%$ & -0.335 & 0.009 & $-2.55 \%$ & -0.197 & 0.009 & $-2.07 \%$ \\
\hline second. Education & 0.034 & 0.001 & $7.87 \%$ & 0.001 & 0.010 & $0.12 \%$ & -0.009 & 0.014 & $-1.91 \%$ & 0.007 & 0.014 & $1.49 \%$ \\
\hline University degree & 0.266 & -0.001 & $32.41 \%$ & 0.270 & 0.013 & $25.99 \%$ & 0.330 & 0.018 & $28.03 \%$ & 0.308 & 0.014 & $19.29 \%$ \\
\hline self-employed & & & & 0.028 & 0.002 & $0.20 \%$ & -0.005 & 0.002 & $-0.03 \%$ & -0.019 & 0.000 & $0.00 \%$ \\
\hline part-time & 0.008 & 0.011 & $-0.60 \%$ & & & & & & & & & \\
\hline housew ife /-man & -0.040 & 0.001 & $-0.80 \%$ & -0.158 & 0.000 & $-0.06 \%$ & -0.204 & -0.001 & $0.60 \%$ & -0.157 & -0.003 & $0.61 \%$ \\
\hline apprentice/student & -0.495 & 0.022 & $-9.93 \%$ & -0.198 & 0.010 & $-5.12 \%$ & -0.197 & 0.009 & $-1.13 \%$ & -0.242 & 0.006 & $-0.31 \%$ \\
\hline retired & -0.136 & -0.005 & $2.54 \%$ & -0.210 & -0.017 & $13.57 \%$ & -0.193 & -0.034 & $32.22 \%$ & -0.144 & -0.036 & $27.13 \%$ \\
\hline unemployed & -0.504 & -0.059 & $3.99 \%$ & -0.198 & -0.016 & $1.07 \%$ & -0.208 & -0.017 & $1.78 \%$ & -0.167 & -0.020 & $1.01 \%$ \\
\hline Espace Mittelland & -0.065 & 0.001 & $-0.57 \%$ & -0.057 & -0.002 & $0.74 \%$ & -0.030 & 0.001 & $-0.26 \%$ & -0.054 & 0.000 & $0.12 \%$ \\
\hline North-West CH & 0.087 & -0.001 & $-0.32 \%$ & 0.076 & -0.011 & $-4.22 \%$ & 0.268 & 0.003 & $0.84 \%$ & 0.064 & -0.007 & $-1.47 \%$ \\
\hline Zurich & 0.217 & 0.011 & $13.32 \%$ & 0.163 & -0.007 & $-6.99 \%$ & 0.079 & 0.000 & $0.19 \%$ & 0.150 & -0.001 & $-0.93 \%$ \\
\hline East $\mathrm{CH}$ & -0.085 & 0.006 & $-3.44 \%$ & -0.018 & -0.005 & $0.41 \%$ & -0.442 & 0.001 & $-0.07 \%$ & -0.091 & 0.000 & $-0.09 \%$ \\
\hline Central $\mathrm{CH}$ & -0.179 & 0.010 & $-6.62 \%$ & -0.038 & -0.006 & $0.76 \%$ & -0.070 & 0.005 & $-0.72 \%$ & -0.036 & 0.002 & $-0.15 \%$ \\
\hline Ticino & -0.204 & -0.018 & $6.65 \%$ & -0.268 & -0.016 & $6.56 \%$ & -0.400 & 0.013 & $-2.76 \%$ & -0.159 & -0.010 & $1.86 \%$ \\
\hline Suppl. Insurance & 0.142 & 0.001 & $1.44 \%$ & 0.124 & 0.006 & $12.75 \%$ & 0.322 & -0.001 & $-1.28 \%$ & 0.242 & 0.002 & $4.07 \%$ \\
\hline $\mathrm{HMO}$ & & & & & & & 0.051 & -0.001 & $-0.25 \%$ & 0.098 & 0.000 & $0.07 \%$ \\
\hline Deductible $300 / 400$ & & & & & & & 0.064 & -0.007 & $-1.90 \%$ & -0.057 & 0.000 & $0.14 \%$ \\
\hline Deductible 600 & & & & & & & 0.003 & -0.001 & $-0.01 \%$ & 0.077 & 0.005 & $1.57 \%$ \\
\hline Deductible 1200 & & & & & & & 0.139 & 0.000 & $0.14 \%$ & 0.158 & 0.007 & $1.42 \%$ \\
\hline Deductible 1500 & & & & & & & 0.200 & -0.014 & $-3.32 \%$ & 0.155 & 0.012 & $7.83 \%$ \\
\hline
\end{tabular}


Figure 1: Health Inequality Indices

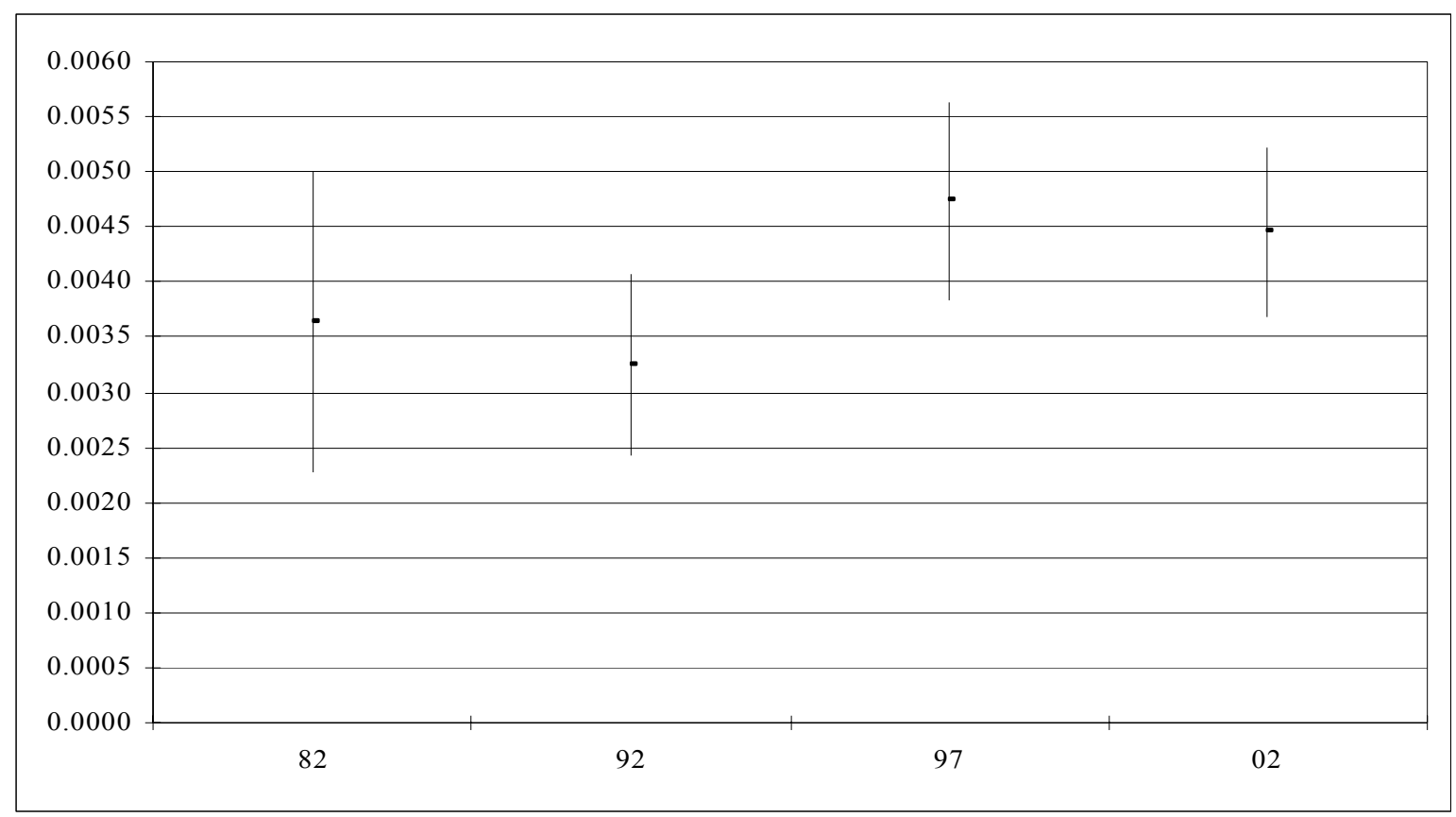

Figure 2: Decomposition of Health Inequalities
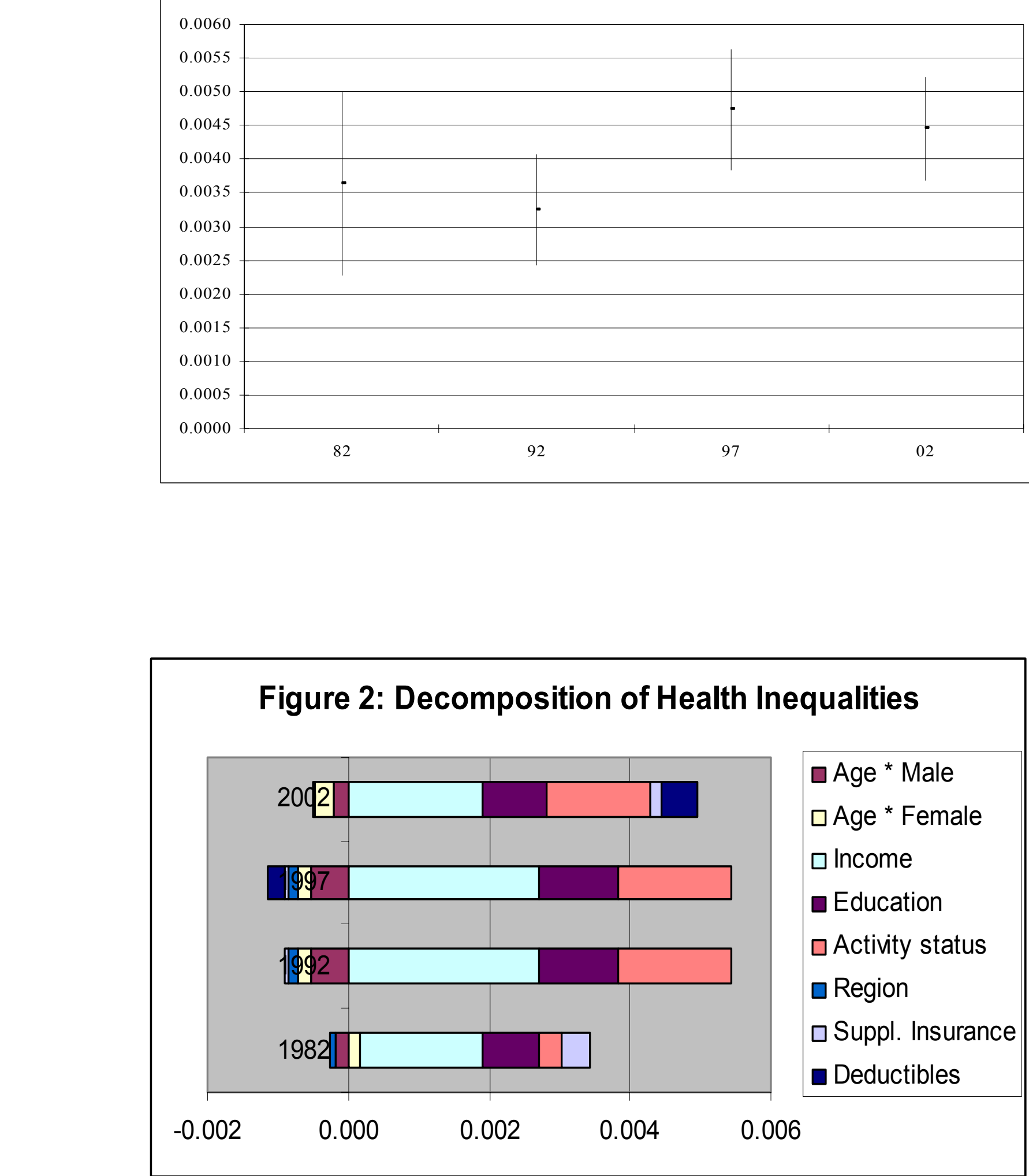